\title{
Entwurf einer Theorie religiös-säkularer Konkurrenz
}

\author{
Jörg Stolz
}

Zusammenfassung: In diesem Artikel werden Grundelemente der Theorie religiös-säkularer Konkurrenz vorgestellt. Die Theorie behauptet, dass Individuen in vielen Gesellschaften zwischen religiösen und säkularen Optionen auswählen können und sich so eine Konkurrenzlage zwischen religiösen und säkularen Anbietern ergibt. Auf der Grundlage einer abstrakten Beschreibung religiöser und säkularer Anbieter und ihrer je unterschiedlichen Güter sowie der Annahme von (begrenzt) rationalem Anpassungsverhalten von Individuen und Organisationen lassen sich Voraussagen über Effekte von Veränderungen der religiös-säkularen Konkurrenzsituation machen. Die wichtigsten Parameter, welche religiös-säkulare Konkurrenz beeinflussen, sind Regulierung des Angebots, Regulierung der Nachfrage und Modernisierungsgrad der Gesellschaft. Die Theorie religiös-säkularer Konkurrenz erklärt eine Reihe ganz unterschiedlicher Phänomene wie etwa Variationen im Kirchgang in US-Staaten, unterschiedliche Anziehungskraft von Klöstern, die späte Säkularisierung Irlands, die starke Religiosität in agrarischen Gesellschaft oder den Erfolg von Megachurches seit den 1960er Jahren.

Schlüsselwörter: Religion $\cdot$ Säkularisierung $\cdot$ Handlungstheorie $\cdot$ Mikrofundierung

\section{Outline of a theory of religious secular competition}

\begin{abstract}
This article presents the basic elements of a theory of religious secular competition. The theory claims that individuals in many societies may choose between religious and secular options, creating a situation of competition between religious and secular organizations. The paper assumes (bounded) rationality for individuals and organizations and describes religious and secular organizations, religious and secular goods, as well as three important parameters that influence religious secular competition: regulation of supply, regulation of demand and level of societal modernization. The theory of religious secular competition explains a whole range of different phenomena, such as variations in church going in US states, variation in the attractivity of monasteries, the late secularization of Ireland, the strong religiosity of agrarian societies or the success of megachurches since the 1960s.
\end{abstract}

Keywords: Religion $\cdot$ Secularization $\cdot$ Theory of action $\cdot$ Micro-foundation

(C) Springer Fachmedien Wiesbaden 2013

J. Stolz $(\bowtie)$

ISSRC-ORS Université de Lausanne,

Quartier UNIL-Dorigny, Bâtiment Anthropole,

Office 2125, 1015 Lausanne, Schweiz

E-Mail: joerg.stolz@unil.ch 
„Statt der betenden Wallfahrtszüge sieht man Sänger,

Turner, Feuerwehrmänner, Schützen, Jahrgänger,

Sonntagsschänder in Gesellschaft moderner Damen

Berg und Thal überfluthen, in ungestümer Hast und

unbezämbarer Gier nach freiem Athem und

Lebensgenuss haschen. "

„Pius-Annalen“, $1875^{1}$

\section{Einleitung}

Der Kontrast könnte grösser nicht sein: Praktiker berichten seit längerer Zeit, dass ihre religiösen Gemeinschaften in einer harten Konkurrenz nicht so sehr mit anderen religiösen Gemeinschaften, sondern mit säkularen Institutionen stehen. Aber die religionssoziologische Forschung hat diese Tatsache bisher kaum beachtet. Pastoren, Priester, Imame, Gemeindeleiterinnen stehen vor der immer schwierigeren Aufgabe, Menschen für ihre Angebote zu interessieren und entwickeln Marketing und Branding Strategien - aber die religionssoziologische Forschung scheint dieser Tatsache gegenüber blind, weil Religion gemäß den Ansichten der meisten Forscher kein „Produkt“ sein kann. Und selbst die „Rational-Choice-Theorie“ der Religion betrachtet mit starrem Blick nur die Konkurrenz zwischen religiösen Gemeinschaften, nicht aber die sehr viel wichtigere zwischen religiösen und säkularen Institutionen.

Dieser Artikel stellt Grundelemente der Theorie religiös-säkularer Konkurrenz vor. Die Theorie behauptet, dass Individuen in vielen Gesellschaften zwischen religiösen und säkularen Optionen auswählen können und sich so eine Konkurrenzlage zwischen religiösen und säkularen Anbietern ergibt. Grundelemente der Theorie sind eine genaue Beschreibung religiöser und säkularer Anbieter wie auch ein Konzept religiöser und säkularer Güter und ihrer Eigenschaften. Es wird von (begrenzt) rationalem Anpassungsverhalten von Individuen und Organisationen ausgegangen, weshalb sich Voraussagen über Effekte von Veränderungen verschiedener Parameter machen lassen. Die wichtigsten Parameter, welche religiös-säkulare Konkurrenz beeinflussen, sind Regulierung des Angebots, Regulierung der Nachfrage und Modernisierungsgrad in einer Gesellschaft. Je nach Ausprägung dieser drei Faktoren kommt es zu anderen individuellen und organisationellen Anpassungsformen und zu unterschiedlichen emergenten Effekten. Die Theorie religiös-säkularer Konkurrenz liefert einen Erklärungsbeitrag zu einer Reihe ganz unterschiedlicher Phänomene auf der Meso- wie auf der Makro-Ebene, so etwa, warum sich die Religiosität in postindustriellen Gesellschaften in den 1960er Jahren so stark verändert hat (sowohl individuell als auch organisationell), warum die USA so viel religiöser ist als Europa, warum postindustrielle Gesellschaften so viel weniger religiös sind als agrarische Gesellschaften, warum Klöster für Frauen mehr oder weniger attraktiv sind oder warum man in den letzten Jahrzehnten einen Boom von Megachurches beobachten kann.

1 Zitiert nach Altermatt (1989, S. 255). 
Die in diesem Artikel behandelten Formen religiös-säkularer Konkurrenz, die auf individuelles Handeln und Erleben zielen (d. h. Konkurrenz um Nachfrage und Image), sind Teil einer allgemeineren Theorie, in welcher auch Fragen der religiös-säkularen Konkurrenz um gesellschaftliche Regeln (d. h. Konkurrenz um die herrschende Ordnung) und Sozialisierung (d. h. Konkurrenz um die Prägung nachwachsender Generationen) einen wichtigen Platz einnehmen. Die beiden zuletzt genannten Punkte bleiben in diesem Artikel jedoch bewusst im Hintergrund.

Das Ziel ist hier mithin nur, einen einzelnen (wenn auch einen wichtigen) Mechanismus unter anderen zu beschreiben, welcher religiöse Phänomene erklären kann. In konkreten Forschungen wird immer zu klären sein, welche Erklärungskraft dieser Mechanismus im Vergleich zu anderen besitzt.

Im Folgenden präsentiere ich zunächst die Vorläufer eines Ansatzes religiös-säkularer Konkurrenz (Abschn. 2), um dann im Hauptteil (Abschn. 3) auf die Grundbegriffe, Mechanismen und Voraussagen der Theorie einzugehen. In Abschn. 4 nenne ich die aus meiner Sicht überzeugendsten bisherigen empirischen Forschungen zum Thema. Abschn. 5 schließt mit einer Zusammenfassung, einer Diskussion ungelöster Probleme sowie mit Empfehlungen für zukünftige Forschung.

\section{Frühere Ansätze}

\subsection{Ein blinder Fleck in der Religionssoziologie}

Die drei wichtigsten soziologischen Theorien, welche Religion in der Gegenwartsgesellschaft behandeln - die Säkularisierungstheorie, die Individualisierungstheorie und die Markttheorie $^{2}$ - haben das Phänomen der religiös-säkularen Konkurrenz bisher kaum oder gar nicht behandelt. Die Gründe hierfür sind nicht schwer zu finden.

Die Säkularisierungstheorie ist im Wesentlichen eine Makrotheorie, welche auf größere gesellschaftliche Modernisierungsprozesse (Differenzierung, Rationalisierung, Sozietalisierung) hinweist, die zu einer Abnahme von Religion führen sollen (Wallis und Bruce 1995). Diese Theorie bekommt religiös-säkulare Konkurrenz nicht in den Blick, da sie die Ersetzung religiöser durch säkulare Funktionen generell beschreibt und damit auf der Makro-Ebene verbleibt. Auch wenn Säkularisierungstheoretiker Aussagen über Säkularisierungsprozesse auf Makro-, Meso- und Mikroebene treffen (z. B. Dobbelaere 2002), geben sie nur selten die spezifischen Mechanismen an, über welche diese Ebenen verknüpft sind. Um einen solchen Mechanismus aber handelt es sich bei der religiös-säkularen Konkurrenz.

Die Individualisierungstheorie behauptet, dass Modernisierung nicht etwa zu Säkularisierung führe, sondern zu einer Veränderung religiöser Formen (Luckmann 1967; Pollack 2008). Zwar befinde sich kirchlich gestützte, institutionelle Religiosität im Rückgang; aber dafür trete eine individualisierte, privatisierte und oft schwer als solche zu erkennende neue Religiosität oder Spiritualität auf den Plan. Zwar finden sich bei Luckmann

2 Siehe zur Unterscheidung dieser drei Ansätze Pollack und Olson (2008); als neueren Überblick Pickel (2011). 
(1967) Ansätze einer Beschreibung religiös-säkularer Konkurrenz. Insgesamt hat aber weder er noch die ihm nachfolgende Literatur dieses Thema ernst genommen. Das liegt zum einen an der sehr weiten funktionalen Religionsdefinition. Diese führte dazu, dass säkulare Konkurrenz nicht als solche erkannt werden konnte, da sie ebenfalls als ,religiös“ bezeichnet wurde. Zum anderen haben Individualisierungstheoretiker vor allem beschreibend und interpretierend gearbeitet und nicht nach kausal-erklärenden Mechanismen gesucht.

Besonders erstaunlich ist, dass selbst die sogenannte Markttheorie bisher die religiössäkulare Konkurrenz kaum zur Kenntnis genommen hat. Vor dem Hintergrund der außermarktlichen Ökonomie (Becker 1990) gehen Markttheoretiker von rationalen Individuen aus, welche religiöse Güter konsumieren (Iannaccone 1998; Stark und Finke 2000). Zwar hat Iannaccone (1988) schon früh ein Modell vorgestellt, in welchem Individuen zwischen religiösen und säkularen Gütern auswählen können. In der nachfolgenden Anwendung auf weitere gesellschaftliche Phänomene wurde dieser Ansatz jedoch aufgrund einer Reihe theoretisch verheerender Annahmen nicht fruchtbar gemacht. Zu diesen Annahmen gehört vor allem, dass die religiöse Nachfrage in allen Gesellschaften konstant sei. Unterschiede der aggregierten Religiosität in verschiedenen Ländern seien daher nur über das Angebot (und daher die Regulierung von Religion) zu erklären. ${ }^{3}$ Sie begründeten dies mit zwei weiteren Annahmen, dass nämlich Güter in allen Gesellschaften knapp seien, weshalb die Individuen immer nach Dingen suchten, die ,nicht in der natürlichen Welt existieren" und dass gerade solche Güter nur durch Übernatürliches postulierende religiöse Organisationen angeboten werden könnten (wie z. B. ein ewiges Leben) (Stark und Iannaccone 1994). Diese Annahmen führten dazu, dass die Markttheoretiker ganz automatisch einen auf religiöse Organisationen beschränkten, ,geschlossenen“ Markt annahmen, da ja nur religiöse Organisationen die transzendenten Güter anbieten konnten. Religiös-säkulare Konkurrenz war dadurch per Definition ausgeschlossen.

\subsection{Vorläufer der Theorie der religiös-säkularen Konkurrenz}

Nicht immer jedoch ist das Phänomen der religiös-säkularen Konkurrenz missachtet worden. In verschiedenen Disziplinen, der Ökonomie, Soziologie, Marketingwissenschaft wie auch Geschichte haben Forscher Ansätze formuliert, welche die religiös-säkulare Konkurrenz aus je unterschiedlicher Perspektive beschreiben.

Ökonomie. Die religionsökonomische Literatur behandelt religiös-säkulare Konkurrenz vorwiegend aus individueller Sicht. Der grundlegende Artikel der „Religionsökonomie“ beginnt mit einem Modell, in welchem Haushalte zwischen religiöser und säkularer Zeitverwendung entscheiden müssen (Azzi und Ehrenberg 1975). In diesem Modell hängt es unter anderem von den Opportunitätskosten religiösen Handelns (z. B. vom zu erwartenden Marktlohn) ab, wie häufig die Individuen in den Gottesdienst gehen. Laurence Iannaccone, der wichtigste gegenwärtige Exponent der Religionsökonomie, hat diese Idee dazu verwendet, die Entstehung von „Kirchen“ und „Sekten“ zu erklären (Iannaccone 1988). Allerdings haben Iannaccone und die ihm nachfolgenden Autoren es verpasst, die Wichtigkeit der religiös-säkularen Konkurrenz für die Erklärung einer Flut von weiteren

3 Daher wurde oft auch vom „supply-side approach“ gesprochen. 
Beispielen zu erkennen. Ausnahmen sind hier die Ökonomen Jonathan Gruber und Daniel M. Hungerman. So hat etwa Hungerman (2010) gezeigt, dass Pastoren aus subjektiver Sicht die Konkurrenz von säkularen Institutionen für ihre Kirchen als sehr viel grösser einschätzten als die Konkurrenz von anderen christlichen Kirchen. Ebenfalls zu nennen ist ein Aufsatz von Anthony Gill und Erik Lundsgaarde (2004), in welchem die Autoren zeigen, dass der säkulare Wohlfahrtsstaat zu einem wichtigen Konkurrenten der (ebenfalls wohlfahrtsstaatliche Leistungen anbietenden) christlichen Kirchen werden kann.

Soziologie. In der Soziologie sind Argumente zur religiös-säkularen Konkurrenz vor allem von zwei Autoren entwickelt worden. Andrew Abbot (1988) hat die religiös-säkulare Konkurrenz in verschiedenen Ländern (v. a. USA, Großbritannien und Frankreich) auf der Ebene der Berufsgruppen analysiert. Er geht davon aus, dass Berufsgruppen versuchen, sich die legitime Behandlung von bestimmten Problemen zu sichern und diese fortan zu verteidigen. Hierbei stützten sie sich auf professionseigene Diagnosen, Inferenzen und Behandlungen der Probleme (Abbot 1988). Die Kleriker müssten sich bei ihrer Arbeit auf einen letzten Wert von „Errettung, Sinn, letzte Fragen“ beziehen, welcher, so Abbot, die Menschen im 20. Jahrhundert immer weniger interessiert habe. Die Kleriker hätten daher versucht, andere Gebiete unter ihren Einfluss und innerhalb ihres Kompetenzbereichs zu bringen. Abbot nennt die Bereiche der sozialen Wohlfahrt, Massenerziehung und Lebensprobleme. In allen diesen Domänen allerdings seien die Kleriker nach anfänglichen Erfolgen von anderen, säkularen Berufsgruppen bekämpft und schließlich wieder ins Abseits gedrängt worden. Beispielsweise hätten die Kleriker im Bereich der Lebensprobleme zunächst mit den Neurologen, dann mit den Psychologen und Psychotherapeuten in einer harten Konkurrenz gestanden. Sie hätten diesen Kampf schließlich vor allem deshalb verloren, weil sie ihre Techniken und Behandlungsmethoden nicht als wissenschaftlich fundiert darstellen konnten.

Auch Pierre Bourdieu (1987) hat in einem Aufsatz auf die religiös-säkulare Konkurrenz hingewiesen, und wie Abbott konzentriert er sich auf die Analyse von Berufsgruppen, die sich gegenseitig die legitime Behandlung von Lebensproblemen streitig machen. Gemäß Bourdieu ist es während des 20. Jahrhunderts zu einer Auflösung des KörperSeele-Schemas gekommen. Hierdurch sei das „religiöse Feld“ aufgelöst worden, um einem weiter ausgreifenden Feld der Symbolbehandlung von Geist und Körper Platz zu machen. Damit, so Bourdieu, seien die Kleriker in eine neue Konkurrenz mit einer großen Anzahl von Berufsgruppen gedrängt worden, welche ebenfalls Geist und Körper mit, nun allerdings säkularen Symbolen behandeln. Bourdieu hat Psychoanalytiker, Sexologen, Körpertherapeuten, Lehrer asiatischer Kampfsportarten, Coaches, Lebensberater usw. im Blick, welche mit ihren Methoden keine „Errettung“ und „ewiges Leben“, wohl aber Heilung, Wohlbefinden und Sinn versprechen.

Marketing. Anders als die Ökonomie und Soziologie behandelt die Marketing-Literatur religiös-säkulare Konkurrenz nicht mit Blick auf Berufsgruppen, sondern auf religiöse Organisationen: Kirchen, religiöse Gemeinschaften und Bewegungen (Mottner 2007). Diese Autoren interessieren sich für die Art und Weise, wie und mit welchem Effekt religiöse Organisationen Marketing und Branding einsetzen. Hierbei gehen sie meist wie selbstverständlich von einer religiös-säkularen Konkurrenz aus. So schreibt etwa Mara Einstein im bisher wichtigsten Buch über religiöses Marketing (2008, S. 9): 
"We shouldn't be surprised then that religion - whether in the form of a film or a church - is being marketed in the current commercialized culture. In order to be heard above the noise of the rest of society, religion, too, must participate in order to survive."

Wie kommt es, dass die Marketingliteratur wie selbstverständlich von religiös-säkularer Konkurrenz ausgeht, während andere Disziplinen Mühe haben, das Phänomen zu erkennen? Der Grund liegt darin, dass die Marketingwissenschaft bedürfnisorientiert denkt. Sie fragt sich, welche Bedürfnisse religiöse Organisationen abdecken und wie die Bedürfnisbefriedigung optimiert werden kann. Stellt man diese Frage, kommt man ganz automatisch auf eine Vielzahl von anderen, säkularen Institutionen, welche ebenfalls Bedürfnisse (wie Sicherheit, Sinn, Integration, Erziehung) befriedigen können und daher mit religiösen Organisationen in Konkurrenz stehen. ${ }^{4}$

Geschichte. Auch in der Geschichtswissenschaft schließlich gibt es eine Reihe von Autoren, die auf die Bedeutung der religiös-säkularen Konkurrenz in westeuropäischen Ländern im 20. Jahrhundert hingewiesen haben. Hugh McLeod (2007), Urs Altermatt (2009) oder Yves Lambert (2007) haben gezeigt, dass neue Freizeitmöglichkeiten wie Tanz, Fußball, Reisen oder Shopping, später Autofahren, Fernsehen, Popmusik und Sex schon seit Beginn des 20. Jahrhunderts und dann vor allem in den 1950er und 1960er Jahren zu gewichtigen Konkurrenten für religiöse Praxis und religiösen Lebensstil wurden. Altermatt (2009, S. 275) berichtet etwa über die Konkurrenz um den Sonntag in der Schweiz folgendes:

„Schon kurz nach dem Zweiten Weltkrieg beschäftigte die Sonntagsheiligung die christlichen Kirche, die 1950 ein gemeinsames Schreiben zum Thema „Sonntag“ herausgaben. Die Debatte drehte sich nicht mehr um die Verletzung der Sonntagsruhe durch Fabrik- oder Feldarbeit, sondern um die Sonntagsheiligung in Konkurrenz zur Freizeitgesellschaft, denn die aufkommende Konsumgesellschaft veränderte das Sonntagsverhalten der Katholiken in radikaler Weise.“

Insbesondere das steigende Realeinkommen der Menschen und die neuen technischen Möglichkeiten (etwa: Fernsehen, Auto) machten diese neuen Lebensweisen erst möglich. Der neue Lebensstil musste zunächst gegen den harten Widerstand der Kirchen und des traditionell gesinnten Teils der Gesellschaft erkämpft werden. Nachdem die Anti-hedonistischen Normen mehr und mehr in sich zusammenfielen, konnte sich dann die Freizeitgesellschaft entfalten und sich von den Städten aufs Land ausbreiten. Interessanterweise reagierten jedoch die Kirchen nicht nur mit Widerstand, sondern zum Teil auch positiv auf die neuen Konkurrenten. Oft versuchten sie zunächst, die neuen Freizeitbeschäftigungen (in moderaten Formen) anzunehmen, selbst zu organisieren und für religiöse Zwecke zu nutzen. So boten die Kirchen seit Beginn des 20. Jahrhunderts immer mehr Reisen, Freizeiten, Sportvereine usw. an. Mit steigendem Angebot und zunehmender Speziali-

4 Im Gegensatz zur Marketing-Literatur denken die meisten Autoren in der religionsökonomischen Literatur nicht von den Bedürfnissen, sondern vom Angebot her. Daher erscheinen ihnen nur Organisationen als Konkurrenz für religiöse Organisationen, welche ähnliche Angebote machen, d. h. andere religiöse Organisationen. 
sierung entglitt den Kirchen allerdings die Kontrolle über den Freizeitmarkt, sodass sie schließlich mit ihren Angeboten nur noch „Anbieter unter anderen“ blieben.

\section{Skizze einer Theorie religiös-säkularer Konkurrenz}

\subsection{Vorbemerkungen}

Die Grundstruktur der Theorie ist in Abb. 1 gezeigt. Bevor die Theorie in den Grundzügen vorgestellt wird, seien vier Vorbemerkungen vorangeschickt, die das Verständnis der Theorie erleichtern sollen.

1) Die hier vorgeschlagene Theorie religiös-säkularer Konkurrenz ist der sogenannten erklärenden oder analytischen Soziologie verpflichtet (Boudon 1974; Esser 1999; Hedström 2005). Soziologie sollte aus Sicht dieses Ansatzes, im Anschluss an Max Weber, rätselhafte soziale Phänomene durch deutendes Verstehen kausal erklären. Hierfür ist es unerlässlich, die genauen Mechanismen herauszuarbeiten, welche zu einem spezifischen zu erklärenden Phänomen geführt haben. Wichtige Elemente der erklärenden/analytischen Soziologie sind das Prinzip des methodologischen Individualismus (oder die sogenannte Makro-Mikro-Makro-Struktur), die Annahme von (begrenzter) Rationalität oder anderen möglichst einfachen Selektionsregeln und die Verwendung von sogenannten „Brückenhypothesen“, welche nötig sind, um Anfangsbedingungen der Erklärungen zu spezifizieren.

2) Die Theorie unterscheidet drei Ebenen: Eine Makro-Ebene gesellschaftlicher Randbedingungen, eine Meso-Ebene der organisationellen und Gruppen-Konkurrenz und eine Mikro-Ebene individueller Anpassungen. Die von der Theorie postulierten Me-

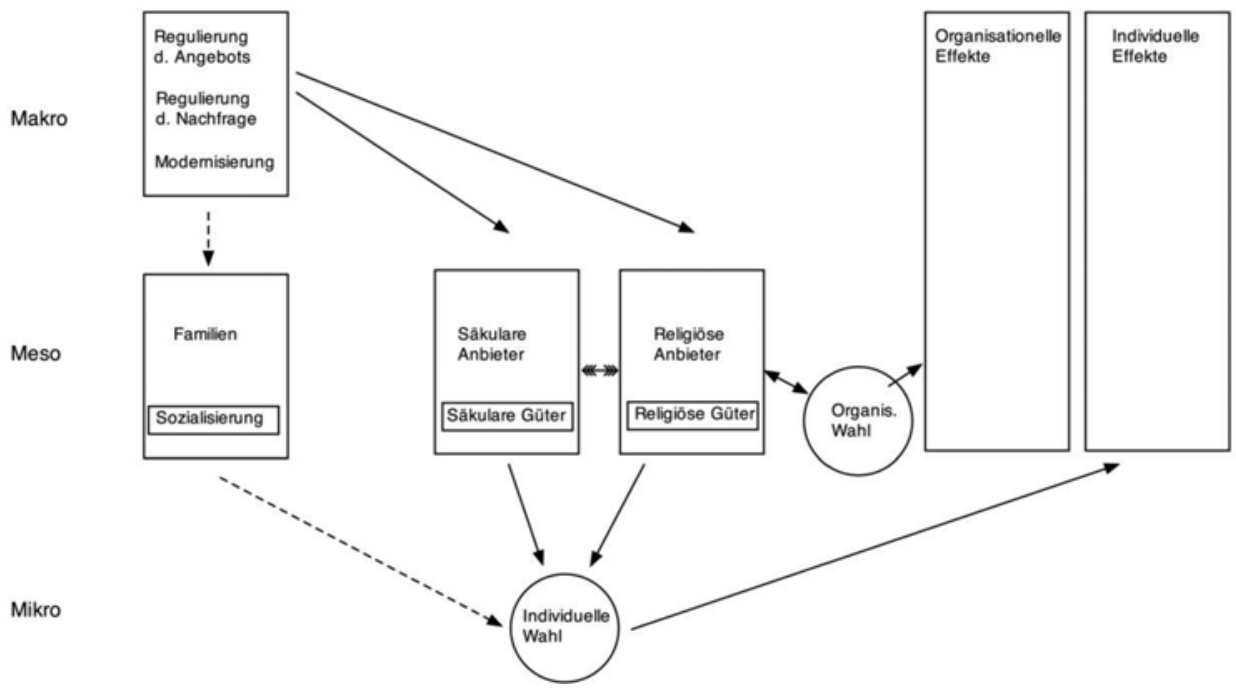

Abb. 1: Die Theorie religiös-säkularer Konkurrenz 
chanismen „wirken kausal“, indem sowohl Individuen als auch (religiöse oder säkulare) Organisationen sich in (begrenzt) rationaler Art und Weise auf ihre Umwelt einstellen und durch Verkettung ihres gemeinsamen Verhaltens wiederum Effekte, die Explananda, entstehen. Trotz des konsequenten methodologischen Individualismus werden Makro-, Meso- und Mikroebene als je konkrete und kausal wirkende Phänomene angesehen. Auf der Makro-Ebene befinden sich etwa für die ganze Gesellschaft geltende Regeln, Ressourcenvorkommen oder Mehrheitsverhältnisse, die über Sanktionen, Verteilungsmechanismen oder Wahrscheinlichkeiten auf tiefere Ebenen (Organisationen und Individuen) wirken. Auf der Mesoebene zeigen sich Organisationen, Gruppen, Familien usw., die als kollektive Akteure aufgefasst werden können und sowohl die Makro- als auch die Mikro-Ebene in vielfältiger Weise beeinflussen können. Auf der Mikro-Ebene treten uns die Individuen gegenüber, die ihrerseits Effekte auf sowohl Meso- als auch Makro-Ebene ausüben. ${ }^{5}$

3) Die zu erklärenden Phänomene der Theorie befinden sich sowohl auf der Meso- als auch der Makro-Ebene und können sich sowohl auf aggregiertes Organisationsverhalten als auch aggregiertes Individualverhalten beziehen. Die Theorie erklärt z. B. warum religiöse Organisationen unter bestimmten Bedingungen beginnen, säkulare Organisationen zu imitieren (Meso-Ebene) genauso wie die Tatsache, dass die USA religiöser sind als Europa (Makro-Ebene). Erklärungen auf dieser Grundlage sind dann immer konkret auf ein spezifisches Phänomen bezogen und in diesem Sinne von „mittlerer Reichweite“ (Merton 1968). Ziel dieses Artikels ist es, Bausteine von verschiedensten möglichen middle-range Theorien zur religiös-säkularen Konkurrenz darzustellen und zu systematisieren (vgl. auch 3.7).

4) Der in diesem Artikel analysierte Mechanismus religiös-säkularer Konkurrenz bezieht sich auf die Nachfrage der Individuen nach religiösen Gütern. Damit ist nur einer von verschiedenen wichtigen Mechanismen benannt, welche in einer umfassenderen Theorie zu behandeln wären. Insbesondere sind auch Mechanismen der religiösen Sozialisierung sehr wichtig (Abb. 1, durch gestrichelte Linien symbolisiert). Außerdem gibt es eine wichtige religiös-säkulare Konkurrenz um die ,herrschende Ordnung“. Hierbei versuchen kollektive und individuelle Akteure, die Makro-Ebene zu beeinflussen, d. h. die Regulierung des Angebots und der Nachfrage zu verändern. Beispielsweise setzen sich Kirchen für die Beibehaltung der öffentlich-rechtlichen Anerkennung ein, während religionskritische politische Parteien eine solche Anerkennung abzuschaffen versuchen. Politische Konflikte rund um Kirchensteuern, Religionsunterricht an öffentlichen Schulen, religiöse Präambeln in Verfassungen, Verbote von bestimmten religiösen Bauten u. ä. können oft als eine solche religiös-säkulare Konkurrenz um die herrschende Ordnung interpretiert werden. Dieser Kampf und diese Konkurrenz finden in der politischen Arena, in den Medien, vor den Gerichten, aber auch innerhalb von Organisationen statt. Wollte man in Abb. 1 die religiössäkulare Konkurrenz um die ,herrschende Ordnung“ symbolisieren, so müsste man Pfeile von den säkularen und religiösen Anbietern sowie von den Individuen nach oben in Richtung Regulierung einzeichnen.

5 Makro-, Meso- und Mikro-Ebenen kann man sich gut am Beispiel von „Spielen“ klarmachen (hierzu: Coleman 1990). 


\subsection{Definition von Religion}

Es ist offensichtlich, dass eine Theorie religiös-säkularer Konkurrenz nur Sinn macht, wenn religiöse und säkulare Phänomene sich unterscheiden lassen. Nun gibt es eine beachtliche Anzahl von Forschenden in der Soziologie, Religionswissenschaft und Ethnologie/Anthropologie, welche vor allem die Schwierigkeit dieser Unterscheidung hervorheben. Der euro- und christozentrische Religionsbegriff sei zu dekonstruieren und könne keinesfalls als methodisches Instrument von Forschungen dienen (Asad 1993). Andere Autoren glauben, dass die Grenze zwischen Religiösem und Säkularem sich in den letzten Jahrzehnten so sehr verwischt habe, dass eine Unterscheidung gar nicht mehr möglich sei. Im Kontrast zu all diesen Autoren bin ich der Meinung, dass es durchaus möglich ist, Religion zu definieren und mit einer solchen Arbeitsdefinition sinnvoll zu arbeiten.

Die hier vorgestellten Definitionen unterscheiden drei Ebenen und lauten wie folgt: Religion ist die Gesamtheit der kulturellen Symbolsysteme, welche auf Sinn- und Kontingenzprobleme mit dem Hinweis auf eine transzendente Realität reagieren. Die transzendente Realität beeinflusst gemäß dieser Symbolsysteme das tägliche Leben, lässt sich aber nicht vollständig kontrollieren. Religiöse Symbolsysteme beinhalten mythische, ethische und rituelle Elemente, wie auch Vorstellungen von Heilsgütern. ${ }^{6}$ Religiöse Organisationen und Gemeinschaften, auf der sozialen Ebene angesiedelt, sind Einheiten mittleren Abstraktionsgrades, welche einen zentralen Bezug zu einer so definieren Religion aufweisen, also etwa eine religiöse Ideologie vertreten, religiöse Güter anbieten, religiöse kollektive Aktivitäten durchführen. Religiosität ist ein individuelles Erleben oder Handeln, insofern als es sich auf ein oder mehrere religiöse Symbolsysteme bezieht. Mit Hilfe dieser Definitionen lassen sich ein methodistischer Gottesdienst, ein muslimisches Gebet oder eine spirituelle Heilungssitzung zwanglos als „religiös“ einstufen, während etwa ein Fußballspiel, ein Rap-Konzert oder Sex als „säkular“ bezeichnet werden können. Folglich ist es auch möglich, religiöse und säkulare Konkurrenten zu unterscheiden und in ihrem Verhältnis zueinander zu analysieren. ${ }^{7}$

\subsection{Religiöse und säkulare Güter}

Vor dem Hintergrund der soeben skizzierten Definition lässt sich bestimmen, wann ein Gut als ein „religiöses Gut“ zu bezeichnen ist. Interessanterweise kann buchstäblich jegliches Gut zu einem ,religiösen Gut“ werden, wenn es mit einem Transzendenzbezug ausgestattet wird. Objekte wie Becher, Kerzenständer oder ein ausgefallener Computer können genauso religiöse Bedeutung erlangen wie Handlungen (Bewegen, Waschen, Sprechen, Atmen), Dienstleistungen (Beraten, Helfen, Bei-Sich-Aufnehmen) oder Tätigkeiten mit anderen (gemeinsames Zuhören, Singen, Schweigen, Tanzen, Essen).

6 Siehe als gute Diskussion zum Thema Riesenbrodt (2007).

7 Eine so definierte Religion gleicht stärker einem Kontinuum als einer dichotomen Unterscheidung. Phänomene können „mehr oder weniger religiös“ sein und empirisch finden sich wichtige Zwischenbereiche. 
Religiöse Güter treten daher in allen typischerweise von den Sozial- und Wirtschaftswissenschaften unterschiedenen Güterarten auf. Es gibt religiöse Konsumgüter (Rosenkranz, Heiligenbild, Kristallpyramide, religiöses Buch, CD, Film), Dienstleistungen (Trauung, Seelsorge, Heilungssitzung), kollektive Aktivitäten (Gottesdienst, gemeinsame Lesung, religiöse Feste) oder Kollektivgüter (religiöse Gebäude, religiöser Friede, religiös legitimierte Sitten). Was aber ist dann das spezifische an religiösen Gütern? Vier typische Eigenschaften lassen sich nennen, von denen nur die erste ein notwendiges Attribut ist.

Transzendenzbezug. Religiöse Güter sind auf Transzendenz bezogene Heilsmittel zur Erlangung von säkularen oder transzendenten Heilszielen (Heilsgütern) (Stolz 2006; Weber 1985). Immer geht es um das „gute Leben“: die Individuen versuchen, sich mit außeralltäglichen, transzendenten Mitteln einen bestimmten Nutzen zu schaffen oder aber Übel abzuwenden. Hierbei kann es sich um transzendente, eventuell in weiter Zukunft liegende Heilsgüter handeln wie ein ewiges Leben, eine bessere Wiedergeburt oder einen Zustand der Errettung. Häufiger geht es in den Religionen aber um ganz konkrete Lebensbewältigung im Hier und Jetzt, um Fruchtbarkeit, Gesundheit, Reichtum, Liebe, Frieden, Nahrung, soziale Achtung, seelisches Gleichgewicht usw. ${ }^{8}$ Hierbei unterscheiden sich verschiedene Religionen allerdings in extremer Weise darin, mit welchen Heilsmitteln diese positiven Zustände erreicht werden sollen und von welchen Übeln die Religion gerade erlösen will.

Gemeinschaftsorientierung/Diffusität. Bei religiösen Gütern handelt es sich meist um Güter, die innerhalb eines bestimmten Symbolsystems und einer bestimmten Gemeinschaft sinnvoll und wirksam sind. Ihr Konsum, die Teilnahme, das In-Anspruch-Nehmen des Gutes oder der Dienstleistung verweist auf die Gemeinschaft oder findet mit anderen Gemeinschaftsmitgliedern statt. Wenn in einer Pfarrei ein Film gezeigt wird, so ist der Besuch nicht nur mit dem Filmkonsum, sondern auch mit der Idee verbunden, dass man sich als Teil der Gemeinschaft darstellt. Wenn der gleiche Film in einem Kino gezeigt wird, geht es normalerweise nur um den Konsum des Films. Eine kirchliche Heirat bindet (in wie immer abgeschwächtem Maße) in eine kirchliche Gemeinschaft oder Konfession ein; eine säkulare Ritualheirat bezieht sich nur auf die Heiratenden selbst. Man kann den gleichen Sachverhalt auch mit dem Begriffspaar „diffus-spezifisch“ beschreiben (Parsons 1991). Religiöse Güter sind oft diffus in dem Sinne, dass immer mehrere Bezüge gegeben sind. Dem Gut haften immer auch gemeinschaftliche und religiöse Bezüge an. Säkulare Güter sind oft spezifischer.

Spezielle Preise. Aufgrund der Diffusität weisen religiöse Güter oft keine Marktpreise auf. Meist wird eine direkte Marktlogik explizit vermieden. Dennoch liegen natürlich, wie praktisch überall im sozialen Leben, soziale Austauschverhältnisse vor, sodass Leistungen mit Gegenleistungen honoriert werden und man zumindest von „Schattenpreisen“ sprechen kann. In manchen Fällen bezahlen die Individuen Kirchensteuern, in anderen Fällen spenden sie für den Unterhalt ihrer religiösen Gemeinschaft, die religiösen Gemeinschaften stellen anschließend die Leistungen gratis für die Mitglieder und weitere

8 Um das „gute Leben“ geht es selbst dann, wenn eine Religion weit in der Zukunft liegende transzendente Heilsziele verspricht (z. B. ewiges Leben, bessere Wiedergeburt). Denn auch diese Güter verhelfen zu einem positiven Gefühl, der „Heilsgewissheit“ (Weber) im Hier und Jetzt. 
soziale Gruppen zur Verfügung. Nur in manchen Fällen bezahlen die Nutznießer eines spezifischen Produktes genau für diese Leistung. Dies kommt oft im Bereich der alternativen Spiritualität vor, wo Kurse und Behandlungen zu Marktpreisen angeboten werden. Es ist auch der Fall im Markt religiöser Objekte (sofern diese nicht durch Querfinanzierung verbilligt werden).

Niedrige Produktionskosten unter wenig modernisierten Bedingungen. Religiöse Güter können mit sehr geringem Aufwand produziert werden, besonders in wenig modernisierten Ländern. Hier sind tatsächlich die ,start-up costs“" von Religionen sehr gering. ${ }^{9}$ Weiter unten wird argumentiert, dass diese Eigenschaften zum Teil erklären, warum religiöse Anbieter mit ihren Gütern in modernen Kontexten einen vergleichsweise schweren Stand haben.

\subsection{Religiöse und säkulare Anbieter}

Eine Theorie religiös-säkularer Konkurrenz muss in einem nächsten Schritt deutlich machen, wer die religiösen und säkularen Anbieter sind, welche miteinander in Konkurrenz stehen.

Als religiöse (oder religiös-spirituelle) Anbieter seien Einzelpersonen, soziale Gruppen (auch Berufsgruppen) und Organisationen bezeichnet, welche sich auf eine „Religion“ beziehen und „religiöse Güter" produzieren. Reformierte Gemeinden, hinduistische Tempel, muslimische Zentren oder Zen-Meditation-Kursleiter sind allesamt religiöse Anbieter in diesem Sinne. Als säkulare Anbieter wiederum gelten all diejenigen Einzelpersonen, sozialen Gruppen und Berufsgruppen, deren säkulare Güter mit religiösen Gütern in Konkurrenz stehen. Wer aber sind die säkularen Konkurrenten von religiösen Anbietern? Man erhält eine Antwort, wenn man sich klarmacht, dass religiöse Anbieter in zweierlei Hinsicht in Konkurrenz mit säkularen Anbietern stehen.

Eine erste Konkurrenzlage betrifft die religiösen Güter. Wann immer ein Bedürfnis von Menschen (Kunden, Nachfragern) sowohl durch ein religiöses Gut als auch durch ein säkulares Gut befriedigt werden kann, ergibt sich eine potenzielle Konkurrenzlage. Wer aufgrund einer Depression ein Bedürfnis nach Hilfe hat, kann das religiöse Gut „Seelsorge“ nachfragen, aber es gibt einen säkularen Konkurrenten im säkularen Gut „Psychotherapie“. Das Bedürfnis nach sozialen Kontakten kann durch das religiöse Gut „Aktive Mitgliedschaft in einer Gemeinde“" befriedigt werden, aber es gibt viele säkulare Konkurrenten: Sportclubs, Vereine aller Art, Nachbarschaftsnetzwerke usw. Je nach betrachtetem Bedürfnis treten andere Konkurrenten von religiösen Gütern in den Blick (Tab. 1).

Eine zweite Konkurrenzlage ergibt sich in Bezug auf Ressourcen. Religiöse Anbieter sind darauf angewiesen, gewisse „organisationelle Bedürfnisse“ zu befriedigen. Sie benötigen Ressourcen, beispielsweise ein bestimmtes Ausmaß an freiwilligen Helfern, Spenden, Legitimität, medialer Aufmerksamkeit usw. Auch in Bezug auf diese Ressourcen stehen sie in Konkurrenz mit verschiedensten säkularen Institutionen. Eine Liste zentraler funktionaler Erfordernisse religiöser Organisationen zeigt schnell die wichtigsten säkularen Konkurrenten (Tab. 2).

9 Siehe zu einer Analyse von „start-up costs“ von Religionen, der ich allerdings nicht immer folgen würde, Stark und Finke (2000). 
Tab. 1: Konkurrenten von religiösen Anbietern in Bezug auf Bedürfnisbefriedigung

\begin{tabular}{ll}
\hline Von Religion behandelte Bedürfnisse & Mögliche säkulare Konkurrenten \\
\hline Kompensation in Deprivationssituationen & Psychotherapie, Beratungen, Wohlfahrtsstaat \\
Sicherheit, Gesundheit, Erfolg & Versicherungen, Wohlfahrtsstaat, Karriere \\
Innerer Friede und Geborgenheit & Sport, Familie \\
Interpretation der Welt, Sinn & Wissenschaft \\
Lebensstrukturierung & Private Feste \\
Soziale Identität, Soziales Kapital & Berufliche Netzwerke, Neue soziale Medien, Vereine \\
\hline
\end{tabular}

Tab. 2: Konkurrenten von religiösen Anbietern in Bezug auf Ressourcen

\begin{tabular}{ll}
\hline Von religiösen Anbietern benötigte Ressourcen & Mögliche säkulare Konkurrenten \\
\hline Zeit, Energie, Commitment & Arbeitswelt, Familie, säkulare Clubs \\
Geld, Spenden & Freizeitaktivitäten, Wohltätige Organisationen \\
Legitimität, Kompetenz & Säkulare Berufsgruppen \\
Plausibilität & Wissenschaft \\
Aufmerksamkeit & Politische Parteien, Säkulare Akteure in Medien \\
Konsum von Konsumgütern & Wirtschaftsunternehmen \\
\hline
\end{tabular}

Nachdem ich so die zwei Seiten der Konkurrenzlage (Güter, Anbieter) beschrieben habe, lassen sich Reaktionen auf die jeweilige Konkurrenzlage systematisieren.

\subsection{Individuelles und organisationelles Anpassungshandeln}

Die hier vorgestellte Theorie baut auf Annahmen über individuelles und organisationelles Anpassungshandeln auf. So nehme ich auf sehr allgemeiner Ebene an, dass Individuen, ceteris paribus und im Aggregat, diejenige Kombination von (religiösen und/oder säkularen) Gütern auswählen, welche ihnen erlaubt, einen möglichst hohen Nutzen zu erreichen. Welche Option vom Individuum gewählt wird, hängt von den Ressourcen, der Verfügbarkeit, dem Preis und der Produktivität der jeweiligen Optionen ab. Diese Annahmen auf individuellem Niveau führen zu Voraussagen beispielsweise folgender Art: Wenn Klöster die einzige Art sind, wie Frauen berufliche Karriere machen können, werden relativ viele Frauen sich einem Orden anschließen, wenn sich die säkularen Berufswege öffnen, sinkt die Attraktivität von Klöstern wieder. Wenn das durchschnittliche Einkommen der Menschen infolge einer Wirtschaftskrise stark zurückgeht, sodass viele sich biomedizinische Behandlungen nicht mehr leisten können, so werden religiöse Heilmethoden vermehrt Zulauf haben usw.

Ferner nehme ich an, dass auch religiöse Organisationen sich, ceteris paribus und im Aggregat, rational verhalten, d. h. versuchen, ihre Ziele so gut wie möglich zu erreichen. Beispiele von Voraussagen lauten dann etwa: Wenn die Individuen plötzlich nicht mehr durch Regulierung der Nachfrage zur Mitgliedschaft oder Partizipation gezwungen werden können, werden sich religiöse Organisationen zunehmend auf Marketing und Branding verlegen, um Mitglieder und „Kunden“ anzuziehen. Wenn die Konkurrenz durch den säkularen Freizeitbereich immer stärker wird, werden viele religiöse Organisationen versuchen, durch steigende Größe konkurrenzfähig zu bleiben (Megachurches) usw. 
Über Rationalitätsannahmen ist viel geschrieben worden und für eine Diskussion fehlt hier der Raum. Unser Modell kommt mit der sehr schwachen Annahme aus, dass Individuen und Organisationen im Aggregat und mittelfristig nach einer für sie als förderlich angesehenen Situation streben. ${ }^{10}$ Es steht außer Frage, dass einzelne Individuen und Organisationen situativ oft hochgradig irrational reagieren. Andererseits ist die (begrenzte) Rationalitätsannahme das sparsamste Mittel, um eine erklärende Theorie zu bauen. An dieser Stelle möchte ich nur auf eine spezifische Kritik eingehen. Bruce (1993, S. 351) hat behauptet, dass Entscheidungen zwischen religiösen und säkularen Gütern, wie sie hier vorausgesetzt wird, unmöglich seien. Er schreibt: „It is clear that ten-pin bowling is not an alternative to worshiping the Lord." Zeit könne nicht als Schattenpreis fungieren „because people do not spend time per se, they spend time doing this or that, and their affective response to what they are doing changes the costs of the units thus ,exhausted"“. Diese Kritik übergeht indessen, dass eine Flut von empirischen Belegen darauf hinweist, dass Individuen die allerverschiedensten Tätigkeiten als Alternativen für religiöse Aktivitäten betrachten können (siehe z. B. Dixon (2007)).

\subsection{Kontexteffekte: Regulierung des Angebots, Regulierung der Nachfrage, Modernisierungsgrad}

Religiös-säkulare Konkurrenz kann unserer Theorie gemäß durch drei zentrale Kontexteffekte auf der Makro-Ebene beeinflusst werden: Regulierung des Angebots, Regulierung der Nachfrage und Modernisierung. Kontextfaktoren dieser Art sind Attribute ganzer Gesellschaften, die eine Vielzahl von Einzelprozessen beinhalten und für konkrete Forschungen vielfältig spezifiziert werden müssen. Im Folgenden seien einige allgemeinen Möglichkeiten skizziert und an Beispielen veranschaulicht.

Regulierung des Angebots. Wir verwenden einen weiten Regulierungsbegriff, welcher sowohl intendierte als auch nicht intendierte Steuerung von Erleben und Handeln umfasst. Gemeint sind Institutionen (Regeln, Normen, Gesetze) welche einerseits vom Staat, andererseits von der Gesellschaft ganz allgemein vorgegeben werden und in dieser Weise die religiös-säkulare Konkurrenz beeinflussen. Im Falle einer Regulierung des Angebots beeinflusst der Staat und die Gesellschaft religiös-säkulare Konkurrenz durch die Veränderung der Situation der Anbieter. Mittel der Regulierung sind sowohl Normen, wie z. B. Gesetze oder Verordnungen, als auch finanzielle Anreize (Steuererleichterungen oder -befreiungen, Direktzahlungen usw.) oder Verleihung von sozialer Legitimität (öffentlich-rechtliche Anerkennung).

Hierbei kann es zu einer Bevorzugung der säkularen Anbieter kommen z. B. durch Verbot oder Behinderung von Religion. Ein Beispiel ist die explizite anti-religiöse Regulierung in der DDR, in der es etwa zur Abschaffung religiöser Erziehung, Auflösung christlicher Jugendbewegungen und der Einführung des wissenschaftlichen Atheismus als Staatsdoktrin kam (Froese und Pfaff 2005). In anderen Fällen können umgekehrt (alle oder einzelne) religiöse Anbieter gegenüber säkularen Anbietern bevorzugt werden.

10 Vgl. zur Idee der Interpretation der Rational-Choice-Theorien als „medium-term theories“: Kroneberg (2011). Es steht außer Frage, dass reale Individuen vom „Homo Oekonomicus“ der Wirtschaftswissenschaften in diverser Weise abweichen (vgl. Esser (1999). 
In der Schweiz kennen gegenwärtig die meisten Kantone ein System der sogenannten „Landeskirchen“, in welchem einige wenige religiöse Anbieter „öffentlich-rechtlich anerkannt" sind und verschiedene Sonderrechte und - pflichten besitzen (sehr wichtig: das Recht, Kirchensteuern einzuziehen), während andere Anbieter diese Rechte nicht besitzen (Pahud De Mortanges 2007). Ein Beispiel aus den USA ist die von der Administration George Bush Jr. eingeführte Praxis des sogenannte „charitable choice“ (Chaves 1999). Diese Gesetzgebung ermöglichte es dem Staat, nicht nur säkulare, sondern auch religiöse Anbieter von sozialen Wohlfahrtseinrichtungen finanziell zu unterstützen. Hier sollte also eine wahrgenommene Benachteiligung religiöser gegenüber säkularer Anbieter aufgehoben werden.

Regulierung der Nachfrage. Geht es um Regulierung der Nachfrage, so beeinflusst der Staat und die Gesellschaft religiös-säkulare Konkurrenz durch Veränderung der Situation der Nachfrager. Mittel der Regulierung sind einerseits staatliche Gesetze und institutionelle Regeln, welche religiöse Nachfrage behindern oder befördern. Um nochmals auf die Schweiz zurückzukommen. Hier etwa galt vor Einführung der Bundesverfassung 1848 in den meisten Kantonen das religiöse Territorialprinzip (cuius regio, eius religio), welches Bewohnern von Kantonen eine spezifische konfessionelle Zugehörigkeit vorschrieb. In der DDR dagegen griff der Staat nicht nur ins Angebot ein, sondern behinderte auch aktiv die Individuen bei der Ausübung religiöser Praxis, etwa indem Kirchenmitglieder bespitzelt wurden, gesellschaftliche Nachteile in Kauf zu nehmen hatten usw. Zur Regulierung der Nachfrage gehören auch explizite oder implizite Formen sozialer Kontrolle. So beschreibt etwa Lambert (2007) eindrücklich, wie in einem kleinen französischen Dorf (Limerzel) in der ersten Hälfte des 20. Jahrhunderts genau beobachtet wurde, wer am Sonntag in der Messe war und wer fehlte. Ebenfalls zu nennen sind gesellschaftliche Hintergrundannahmen, ein Punkt, auf welchen Berger (1990) und neuerdings Taylor (2007) hingewiesen haben. Dass man etwa zwischen „religiösen“ und „säkularen“ Optionen überhaupt wählen kann, ist gesellschaftlich und kulturell keineswegs selbstverständlich und verdankt sich einer komplizierten, über Jahrhunderte sich hinziehenden Entwicklung. Dass etwa Konfessionslosigkeit ein „normaler“ individueller Zustand sein kann, ist in vielen europäischen Gesellschaften erst seit den 1960er Jahren der Fall.

Schließlich ist bezüglich der Regulation der Nachfrage auch an die Wirkung von Mehrheitsverhältnissen zu denken. Nur schon die Tatsache, dass eine bestimmte (säkulare oder religiöse) Option von einer Mehrheit von Menschen gewählt wird, hat wichtige soziale Konsequenzen für das Verhalten der Einzelnen. Was die Mehrheit tut, wirkt meist „normal“" und nachahmungswürdig; die Anpassung erleichtert den sozialen Kontakt. ${ }^{11}$

Regulierung von Angebot und Nachfrage können in die gleiche Richtung weisen. Es kann jedoch auch zu Mischformen kommen. In den USA vor 1960 war etwa das Angebot stark dereguliert, die Nachfrage jedoch stark reguliert. Es war wichtig, eine Religion zu haben, aber weniger wichtig, welche (siehe zu diesem Beispiel unten).

Modernisierungsgrad. Der Modernisierungsgrad beeinflusst die religiös-säkulare Konkurrenz durch die (Nicht-) Verfügbarkeit, die Produktivität und die Plausibilität von religiösen oder säkularen Optionen sowie durch die den Individuen zur Verfügung stehen-

11 Siehe zu Mechanismen dieser Art Kelley und de Graaf (1997) und Pollack und Müller in diesem Band. 
den Ressourcen (Norris und Inglehart 2004). Als Modernisierungsgrad bezeichne ich den Grad der Entwicklung einer Gesellschaft auf einer Dimension, welche ganz verschiedene Prozesse beinhaltet, wie etwa das durchschnittliche Realeinkommen, die medizinische Versorgung, Alphabetisierung usw. (Inglehart und Welzel 2005). Der Modernisierungsgrad kann etwa mit dem Human Development Index gemessen werden.

Die vier oben genannten Eigenschaften religiöser Güter (Transzendenz, Diffusität, spezielle Preise, niedrige Produktionskosten) zeigen, dass Modernisierung religiöse Güter in eine zunehmend schwierige Lage bringt. Transzendenz wird immer unplausibler, der Trend geht weg von Diffusität zu Spezifik, hin zu Marktpreisen und der Vorteil der niedrigen Produktionskosten in armen Ländern schwindet durch steigendes Volkseinkommen. Dies heißt jedoch nicht, dass es in der Moderne keine religiösen Güter mehr gäbe. Sie sind immer noch gegeben, können als Nischenprodukte überleben und je nach Konjunktur mehr oder weniger Erfolg haben.

\section{Explananda}

Die Theorie religiös-säkularer Konkurrenz erklärt eine ganze Reihe von Phänomenen auf verschiedenen Ebenen sozialer Realität, welche bisher vor allem beschrieben, aber noch nicht erklärt worden sind. Sie schlägt ferner neuartige Erklärungen für altbekannte religionssoziologische Rätsel vor. In wieder anderen Fällen integriert sie schon bestehende Erklärungen in ein allgemeineres theoretisches Schema.

Im Folgenden skizziere ich die Anwendung der Theorie auf allgemeiner theoretischer Ebene anhand von sechs Beispielen. Hierbei handelt es sich bei den ersten drei Beispielen um ganz allgemeine Phänomenbereiche, in welchem bisherige Forschungsbefunde eine Erklärung im Sinne religiös-säkularer Konkurrenz aussichtsreich erscheinen lassen, bei den letzten drei Beispielen dagegen um schon vorliegende konkrete Studien, welche das Konzept religiös-säkularer Konkurrenz erfolgreich angewandt haben.

Ein erster Phänomenbereich, in welchem die Theorie religiös-säkularer Konkurrenz wichtige Erklärungen vorlegen kann, betrifft die Veränderung der Religion in postindustriellen Gesellschaften in den 1960er Jahren. Die Theorie behauptet, dass es in den 1960er Jahren erstens zu einem Zusammenbruch der Regulierung der Nachfrage (Zerfall religiöser Normen), zweitens zu einer extremen Ausweitung der säkularen Optionen und drittens zu einem starken Anwachsen individueller Ressourcen gekommen ist. Einerseits musste man nicht mehr in die Kirche gehen, andererseits hatte man plötzlich viel mehr Einkommen und säkulare (z. B. Freizeit-) Möglichkeiten zur Verfügung. Hierdurch setzte eine extrem starke religiös-säkulare Konkurrenz ein, in welcher die religiöse Seite oft das Nachsehen hatte. Dies wiederum führte sowohl auf individueller wie auch auf organisationeller Ebene zu interessanten Anpassungen, was eine Flut von Phänomenen erklärt. Ich gehe zunächst die Effekte auf individuelle Religiosität ein.

Individuelle Effekte. Ein erster, in der Literatur vielfach beobachteter Effekt liegt in sinkendem Interesse für Religion und sinkender religiöser Praxis. Eine wachsende säkulare Konkurrenz kann dazu führen, dass Individuen säkulare statt religiöse Optionen wählen, was zu absinkender religiöser Praxis führt. Ist diese säkulare Praxis erst einmal habitualisiert, finden Individuen Religion dann gar nicht mehr „,wichtig“. Eine große Anzahl von 
Studien hat derartige Effekte nachgewiesen. So konnte gezeigt werden, dass vermehrte Einkaufsmöglichkeiten, bessere Berufschancen, ein Ausbau des Wohlfahrtsstaats oder auch säkulare Beerdigungsmöglichkeiten zu einer sinkenden Nachfrage nach religiösen Ritualen und religiösen Berufen führte (Ebaugh et al. 1996; Gill und Lundsgaarde 2004). Natürlich schließen sich säkulare oder religiöse Optionen oft nicht aus. Man kann etwa Kirchenmitglied bleiben, aber sich aktiv vor allem im Fußball oder Rotary engagieren. Im Effekt führt dies zu einer sogenannten ,distanzierten Religiosität““ (Stolz et al. 2013).

Ein zweiter Effekt liegt in neuartigen typischen Erwartungshaltungen gegenüber Religion. In Konsumgesellschaften mit freier Wahl und sowohl säkularen als auch religiösen Optionen lernen Individuen, dass grundsätzlich alle Produkte und Dienstleistungen auf ihre Bedürfnisse abgestimmt sein sollten. Sie erwarten daher zunehmend qualitativ hochwertige und unterhaltende Gottesdienste, erstklassige religiöse Musik, charismatische Pastoren und Redner wie auch bequeme Zugangs- und Parkmöglichkeiten vor den religiösen Gebäuden (Einstein 2008). Individuen weigern sich außerdem zunehmend, verhaltensregelnde Normen zu akzeptieren. Genau wie in der Welt des säkularen Konsums möchten sie aufgrund individueller Präferenzen auswählen, was ihnen gefällt, anstatt sich Gedankengut und Verhaltensweisen aufoktroyieren zu lassen.

Ein dritter Effekt schließlich liegt im Aufkommen von säkular-religiösen und hybridreligiösen Glaubens- und Praxisformen. Die säkulare Konkurrenz bewirkt, dass die Individuen bestimmte religiöse Glaubensinhalte und Praxisformen mit säkularen Ansichten und Praxisformen in ganz eigenständiger Weise vermischen (Stolz und Usunier 2013). Knoblauch (2009) bezeichnet dieses Phänomen als „populäre Religion“. Meist unter Zuhilfenahme bestimmter Konsumgüter statten die Menschen bestimmte Handlungen, Objekte oder Personen mit eine „heilige“ Dimension aus. Ganz individuell werden ihnen etwa Sport, die Verehrung eines Pop-Idols, Shopping oder eine Marke zu etwas Verehrungswürdigem oder gar „Heiligem“ (säkulare Spiritualität). Oder aber sie interessieren sich für sogenannte hybride Religionen und Spiritualitäten, d. h. Phänomene, welche sich bewusst in einem unscharfen Gebiet zwischen Religion und Säkularität aufhalten. Beispiele sind etwa die Rave Kultur, Sacred Sex, Wellness, Dianetik, Mindfulness, Astrologie oder die Star Wars Religion.

Organisationelle Effekte. Auch auf organisationeller Ebene finden sich wichtige Effekte religiös-säkularer Konkurrenz. Erstens werden religiöse Organisationen durch die säkulare Konkurrenz dazu gezwungen, Marketing- und Brandingtechniken zu verwenden. Eine große Anzahl von Studien zeigt, dass religiöse Organisationen vor allem seit den 1960er Jahren immer stärker mit Marketing reagieren: sie erforschen Konsumentenbedürfnisse, entwerfen neue Ritualformen, werben mit Plakaten, Radio- und TV-spots (Einstein 2008). Ein solches Organisationsverhalten zeigt sich keineswegs nur bei christlichen Gruppen. Ein auf den Hinduismus zurückgehendes Beispiel ist etwa das erfolgreiche Marketing von Yoga im Bereich der „Wellness“.

Zweitens können religiöse Organisationen auf die säkulare Konkurrenz auch durch Aufbau von Megachurches reagieren. Da die Kunden eine höhere Qualität in allen möglichen Bereichen erwarten, fallen zusätzliche Kosten an, welche nur durch größere Strukturen mit einer großen Anzahl von Mitgliedern und Besuchern aufgefangen werden kann 
(Chaves 2006). ${ }^{12}$ Gegenüber einer starken säkularen Konkurrenz können Kirchen also nur bestehen, wenn sie auf Größe setzen, sodass sie sich etwa Chöre, Sound-Anlagen, Gebäude usw. leisten können, die den Menschen als attraktiv erscheinen. Aus analogen Gründen kommt es in Konfessionen, die ein Territorialsystem besitzen, zu Gemeindefusionen. Wiederum ist das Argument, dass ein konkurrenzfähiges Angebot nur durch eine gewisse „kritische Masse“ sowohl an Ressourcen als auch an potenziellen Besuchern möglich wird (Stolz und Ballif 2010).

Ein dritter Effekt besteht darin, dass religiöse Organisationen beginnen, erfolgreiche Konkurrenten im säkularen Bereich zu imitieren, um sowohl für ein religiöses als auch für ein säkulares Publikum attraktiver zu werden. Der Gottesdienst wird zur „Celebration“, die Predigt wird zur unterhaltenden „Message“, voller Humor, Bewegung und Theatereinlage. Viele Pastoren und vor allem Tele-Evangelisten kopieren den Stil von bekannten Late-Night-Unterhaltern wie Johnny Carson oder Jay Leno (Moore 1994). Viele erfolgreiche Megachurches verwenden qualitativ hoch stehende Pop- und Rockbands (z. B. Vineyard, Hillsong, ICF). Viele esoterische Anbieter kopieren Elemente der Wissenschaft, indem sie ihre Organisationen „Institute“ nennen, welche „Seminare“ abhalten und „Konferenzen“ organisieren (Hero 2010). Wenn das Kopieren erfolgreich verläuft, kann es zu sogenannten „,cross-over-Phänomenen“ und zu einem „Verwischen der Grenzen“ (,,blurring“) kommen. Dann haben religiöse Produkte im säkularen Bereich Erfolg (z. B. die „Left Behind Serie“, Ferien im Kloster, die Heilsarmee am Eurovision Song Contest) oder aber säkulare Produkte im religiösen Bereich (z. B. rap music in den sogenannten Black Churches).

Ein vierter Effekt besteht darin, dass religiöse Organisationen sich explizit darum bemühen können, ihren Mitgliedern einen relativ geschlossenen Lebensbereich anzubieten, innerhalb welchem sie vor vielen säkularen Angeboten geschützt werden, oder innerhalb welchem sie ihr Leben führen können, ohne mit diesen Angeboten in Berührung kommen zu müssen. Stolz et al. (2012) haben dies am evangelikalen Milieu in der Schweiz gezeigt. Ganz ähnliche Phänomene finden sich aber auch im ultra-orthodoxen Judentum und vielen anderen religiösen Traditionen.

Die Theorie religiös-säkularer Konkurrenz liefert auch, um zu einem zweiten Phänomenbereich überzugehen, eine spezielle Erklärung für den bekannten Unterschied zwischen der Religiosität in den USA und Europa. Die sehr hohe Religiosität der USA trotz starker Modernisierung und Mobilität hat die Sozialwissenschaften seit langer Zeit beschäftigt; schon die Klassiker wie Smith, Tocqueville und Weber haben sich mit diesem Phänomen auseinandergesetzt. Es besteht kein Zweifel, dass sich in den USA im ganzen 20. Jahrhundert (aber auch schon in früheren Jahrhunderten) eine höhere Religiosität findet als in den meisten europäischen Ländern (Norris und Inglehart 2004; Putnam und Campbell 2010). Für die klassische Säkularisierungstheorie konnte die USA nur als Anomalie gelten, aber auch die zunächst plausibel erscheinende Erklärung der Markttheorie ist unterdessen stark in Zweifel gezogen worden (Bruce 1999).

Unsere Theorie religiös-säkularer Konkurrenz liefert hier eine neue Erklärungsperspektive. Wir erklären die höhere Religiosität in den USA (vor allem vor den 1960er

12 Ich rekonstruiere die Studie von Chaves hier relativ stark. Im Artikel erscheint die religiös-säkulare Konkurrenz nur implizit. Mir scheint diese Interpretation jedoch evident. 
Jahren) durch zwei Punkte. Erstens war in den USA zwar das religiöse Angebot frei, die religiöse Nachfrage blieb jedoch seit Gründung der USA reguliert, d. h. es war sozial sehr wünschenswert, religiös zu sein und einer religiösen Gemeinschaft anzugehören. Hier liegt ein Punkt, der oft nicht verstanden wurde. Zwar herrscht in der Tat eine strikte Trennung zwischen „Kirche und Staat“, es gibt keine „established churches“ (Erster Zusatz der Verfassung), was ich als „Deregulierung des religiösen Angebots“ bezeichne. Dennoch herrschte von Anbeginn der USA eine starke soziale Erwartung, dass Individuen religiös zu sein hätten, einer Kirche angehören sollten und nur so soziale Achtung erreichen konnten. Dies wiederum hatte historische Gründe. Die USA ist eine vergleichsweise sehr junge Nation, welche gerade in ihrer Aufbauzeit neue Normen benötigt und ihre Integration über eine Ideologie, den „Amerikanismus“, bewerkstelligt (Hoover 1991; Lipset 1991). In diese Ideologie wurde „Religion“ von Anfang an mit eingebaut (so wie die Laïcité in die Ideologie der französischen Republik integriert wurde). Eine solche Situation musste zu starker interner religiöser Konkurrenz und hoher Religiosität führen. Da die Menschen nicht ins Säkulare ausweichen konnten, war die Frage nicht, ob sie religiös sein wollten, sondern welches religiöse Angebot sie wählen wollten. Zur gleichen Zeit war in Europa vor den 1960er Jahren eine Situation von sowohl reguliertem Angebot als auch regulierter Nachfrage zu finden, eine Situation, in welcher wenig Dynamik möglich war und die Religion tendenziell durch Modernisierung ausgehöhlt wurde.

Zweitens ist die US-amerikanische Gesellschaft seit ihren Anfängen zutiefst liberal (oder libertär). Die Gesellschaft sollte, so die Meinung großer Mehrheiten, durch den Markt reguliert werden. Ein minimal ausgebauter Staat sollte dem Individuum ein Maximum an Rechten garantieren. Die Rechte auf freie Rede, freies Wirtschaften, freien Waffenbesitz, freie Religionsausübung, freie Wahl der Kranken- und Lebensversicherung usw. wurden daher von Anfang an extrem stark gewichtet. Daher ist der Sozial- und Wohlfahrtsstaat in den USA sehr viel geringer ausgebildet als in vergleichbaren Staaten. Dies wiederum hatte zur Folge, dass der Wohlfahrtsstaat die Kirchen als Produzenten von Wohlfahrtsgütern nicht aus dem Feld schlagen konnte, wie in vergleichbaren postindustriellen Ländern (Gill und Lundsgaarde 2004).

Ab 1960 trat sowohl in den USA als auch in Europa eine neue Situation ein. In Europa kam es nach 1960 zu einer völliger Deregulierung der Nachfrage bei weiterhin reguliertem Angebot, was zu extremer Säkularisierung führte. In den USA wurde die Nachfrageregulierung ebenfalls schwächer, aber insgesamt konnte das religiöse Angebot (bis jetzt) doch einen wichtigen Platz in der Gesellschaft verteidigen, da es im Konkurrenzkampf gestählt worden war.

Eine weitere von der Theorie religiös-säkularer Konkurrenz produzierte Erklärung betrifft den Befund, dass Religion, religiöse Glaubensüberzeugungen und religiöse Praxis in agrarischen Ländern so viel höher ist als in postindustriellen Ländern (Norris und Inglehart 2004). In agrarischen Ländern findet sich ein sehr niedriges Bruttosozialprodukt und hohe Risiken aller Art (medizinische, politische, geologische usw.) für Individuen. Diverse Bedürfnisse sind daher nicht gedeckt und die Menschen haben weder die säkularen Optionen noch die Ressourcen, um hier Abhilfe zu schaffen. In einer solchen Situation haben religiöse Anbieter mit ihren geringen Produktionskosten einen immensen Vorteil und können religiöse Güter anbieten, welche die Befriedigung diverser Bedürfnisse durch transzendente Heilsmittel versprechen. In postindustriellen Gesellschaften dagegen lie- 
gen eine Vielzahl hoch wirksamer säkularer Optionen vor und die Menschen verfügen über genügend Ressourcen, sich diese auch zu leisten. Säkulare Optionen verdrängen daher tendenziell die religiös-magischen. Ein gutes Beispiel ist spirituelle Heilung, welche sowohl in westeuropäischen als auch in afrikanischen Ländern in Konkurrenz zu biomedizinischer Behandlung steht. In beiden Kontexten steht ein diffuses System holistischer Heilung, welches Körper, Seele, Lebensumstände und transzendente Mächte gemeinsam behandelt, einem extrem spezifischen biomedizinischen System gegenüber, welches Krankheiten auf einzelne, wissenschaftlich belegte, Ursachen zurückführt und das Gesamtziel der „Heilung“ aufgegeben hat (Dow 1986; Kiefer 2007). In den afrikanischen Ländern jedoch hat die spirituelle Heilung (teils traditionell verankert, teils pfingstlich orientiert) einen riesigen Zulauf, während sie in westeuropäischen Ländern ein Nischendasein fristet (Anyinam 1997). Dies ist zweifellos durch verschiedene Faktoren zu erklären. Die in der Gesellschaft vorherrschende Weltsicht spielt eine Rolle, die institutionellen Regeln sind ebenfalls von Belang. Ein wichtiger Teil der Erklärung liegt aber wiederum im hier behandelten Mechanismus, nämlich dass in westafrikanischen Ländern oft entweder säkulare, biomedizinische Einrichtungen fehlen oder die entsprechenden Behandlungen nicht erschwinglich sind (Ukah 2008).

Eine der interessantesten Studien zu religiös-säkularer Konkurrenz bezieht sich auf individuelle Zeitverwendung und stammt von Gruber und Huberman (2008). Die Studie ist deshalb vorbildlich, weil sie eine historisch bedingte Manipulation der unabhängigen Variable verwendet, um ein Quasi-Experiment durchzuführen. Auf diese Weise kann der Effekt einer Veränderung der religiös-säkularen Konkurrenz auf Religiosität direkt und unter Konstanthalten anderer Variablen gemessen werden. Gruber und Huberman verwendeten die Tatsache, dass in 16 US-Bundesstaaten je zu unterschiedlichen Zeitpunkten zwischen 1955 und 1985 sogenannte „blue laws“ abgeschafft wurden. „Blue laws“ verboten in den entsprechenden Staaten Erwerbsarbeit und Verkauf an Sonntagen. Die Autoren stellten fest, dass die Abschaffung der Gesetze (und folglich der Beginn von Sonntagsverkauf und Sonntagsarbeit) unter Katholiken und Protestanten zu einem signifikanten Sinken der Kirchganghäufigkeit in den betreffenden US-Bundesstaaten führte. Anstatt in die Kirchen zog es augenscheinlich immer mehr Menschen in die Konsumtempel. Die Ergebnisse zeigen, dass die Abschaffung der „,blue laws“ nicht so sehr zu einem völligen Ausstieg von bisher nur spärlich in die Kirche Gehenden führte, sondern vor allem eine Reduzierung der Kirchganghäufigkeit von bisher regelmäßig Gehenden bewirkte. Die Autoren kommentieren:

"The repeal of these laws in cities and states substantially increases the opportunity cost of religious attendance by offering alternatives for work, leisure, and consumption" (Gruber und Hungerman 2008, S. 832).

Ein nächstes Beispiel wurde von Ebaugh $(1993,1996)$ zur Attraktivität von Frauenklöstern vorgelegt. Sie zeigt, dass in den USA ab der Mitte des 20. Jahrhunderts die Zahlen der jungen Frauen abnehmen, welche sich dazu entscheiden, Nonne zu werden. Ferner kann sie belegen, dass die Frauenorden weltweit in armen Gegenden der Welt wachsen, während sie in reichen Gegenden der Welt rapide schrumpfen. Die Erklärung liegt wiederum in einer religiös-säkularen Konkurrenzsituation. Im 19. Jahrhundert und zu Beginn des 20. Jahrhunderts war die Karriere als Nonne in westlichen Ländern wie den USA 
relativ attraktiv; es gab für Frauen kaum andere Möglichkeiten, höhere berufliche Stellungen und höhere Bildung zu erlangen. Mit der Öffnung des Arbeitsmarktes für Frauen verschwand dieser relative Vorteil. In ärmeren Gegenden der Welt ist dieser Vorteil heute noch vorhanden.

"Throughout the nineteenth and early twentieth centuries, religious orders provided
an avenue of social mobility for Catholic girls who, like most women in our society,
had little or no opportunity for advanced educations and careers. The one exception
was Catholic sisters, who tended to have more education than did laywomen at
the time, and who had careers as teachers or nurses. Joining a convent, therefore,
not only provided opportunities for young Catholic women but also brought status
to the family blessed with having a daughter called to the convent" (Ebaugh et al.
1996, S. 174).

Ein letztes Beispiel betrifft die verspätete Säkularisierung Irlands. Anders als in anderen westeuropäischen Ländern zeigte sich in Irland während Jahrzehnten eine extrem hohe aggregierte Religiosität. Wie Hirschle (2010) zeigt, fällt der Niedergang der religiösen Praxis zwischen 1989 und 2005 genau mit einem extremen Wirtschaftswachstum zusammen. Hirschle interpretiert diesen Sachverhalt im Sinne einer religiös-säkularen Konkurrenztheorie. Das Wirtschaftswachstum habe die individuelle Kaufkraft und den Konsum der Individuen verstärkt, wodurch die Menschen in eine nichtreligiöse symbolische Weltkonstruktion eingetreten seien. Hirschle erklärt:

"[...] the consumption opportunities that accompanied economic growth in Ireland redirected the population's social behavioral patterns from religious to consumption-related routine activities [...]" (Hirschle 2010, S. 9). ${ }^{13}$

\section{Diskussion und Ausblick}

In diesem Artikel habe ich die Grundelemente der Theorie religiös-säkularer Konkurrenz vorgestellt. Ich habe behauptet, dass Individuen in vielen Gesellschaften zwischen religiösen und säkularen Optionen auswählen können und sich so eine Konkurrenzlage zwischen religiösen und säkularen Institutionen ergibt. Religiös-säkulare Konkurrenz, so meine These, erklärt eine Reihe ganz unterschiedlicher Phänomene, wie etwa Variationen im Kirchgang in US-Staaten, unterschiedliche Anziehungskraft von Klöstern, die späte Säkularisierung Irlands, die starke Religiosität in agrarischen Gesellschaft oder den Erfolg von Megachurches seit den 1960er Jahren. Im Sinne eines Ausblicks möchte ich noch drei Punkte anfügen.

Ein erster Punkt betrifft die Reichweite und die Grenzen des Ansatzes. Es ist klar, dass mit der Konkurrenz zwischen religiösen und säkularen Optionen, welche von Individuen nachgefragt werden können, nur ein kausaler Mechanismus unter anderen beschrieben worden ist. Ein einzelner kausaler Mechanismus erklärt ein spezifisches Phänomen nie

13 Hirschle versucht diesen Ansatz von einem Säkularisierungsmechanismus abzugrenzen, was mich weniger überzeugt. Eine gute Kritik liefert Voas (2010). 
vollständig, sondern muss immer durch andere kausale Mechanismen ergänzt werden. Einige wichtige, hier nicht oder nur am Rande erwähnten weiteren Mechanismen sehe ich in der Konkurrenz um die herrschende Ordnung ${ }^{14}$ (d. h.: welche religiösen oder säkularen Regeln sollen gelten?), die, stark mit dem ersten Punkt verbundene Konkurrenz um religiöse oder säkulare Sozialisierung/Erziehung, den wissenschaftlichen/technischen Fortschritt und weitere historische Faktoren. Hier wird also keine neue Gesamterklärung und auch kein neuer „Master-Faktor“ vorgelegt, der alles oder das meiste der Varianz zu erklären beansprucht. Ich bin aber durchaus der Meinung, dass die Varianz sehr vieler Phänomene auch durch religiös-säkulare Konkurrenz (mit-)erklärt wird.

Ein zweiter, mit dem ersten zusammenhängender Punkt betrifft das Verhältnis des hier vorgestellten Ansatzes zur Säkularisierungstheorie. Handelt es sich um einen Alternativansatz, welcher der Säkularisierung widerspricht? Keineswegs. Aus meiner Sicht ist der hier vorgestellte kausale Mechanismus einer von verschiedenen Faktoren, welcher Säkularisierung erklärt (und nicht nur beschreibt). Wer etwa Säkularisierung auf einer Makro-Ebene durch Differenzierung erklärt, verbleibt in einer reinen Beschreibung der Phänomene, da die beiden Phänomene nicht voneinander zu trennen sind. Eine handlungstheoretische Erklärung muss zeigen, aus welchen Gründen es zu einer Säkularisierung, z. B. einer Ausdifferenzierung von religiösen und säkularen Handlungsfeldern kommt. Der in diesem Artikel gezeigte Mechanismus ist ein solches Element, denn das Spiel von Angebot und Nachfrage kann Säkularisierung vorantreiben. Wie sich oben gezeigt hat, ist etwa die sinkende Zahl von Nonnen, der abnehmende Kirchgang in den Staaten der USA usw. auf religiös-säkulare Konkurrenz zurückzuführen. Im Unterschied zur bisherigen Säkularisierungstheorie erfolgt diese Erklärung jedoch in einem MakroMikro-Makro-Schema der analytischen Soziologie und erfüllt damit die Anforderungen der handlungstheoretischen Erklärung. In genau analoger Weise kann der hier vorgestellte Mechanismus auch gewisse Phänomene der religiös-säkularen Ausdifferenzierung erklären. Beispielsweise setzte in Frankreich in den 1930er und 1940er Jahren die Konkurrenz säkularer Sportvereine katholische Sportvereine immer mehr unter Druck, zwang sie zu einer stärkeren Professionalisierung und drängte schließlich das religiöse Element immer weiter in den Hintergrund, sodass es gesamthaft zu einer stärkeren Ausdifferenzierung kam (Munoz 2003). ${ }^{15}$

Ein dritter Punkt bezieht sich auf zwei empirische Anomalien und ein Identifikationsproblem des Ansatzes religiös-säkularer Konkurrenz. Eine erste Anomalie besteht darin, dass verschiedene Studien eine positive Korrelation zwischen säkularen und religiösen Aktivitäten finden (z. B. Putnam 2000). Wenn aber säkulare und religiöse Aktivitäten ein funktionales Äquivalent sind, so sollte doch eine negative Korrelation zu erwarten sein. Dieser Sachverhalt lässt sich meines Erachtens so erklären, dass die positiven Korrelationen normalerweise in Querschnittsstudien gefunden werden. Sie kommen

14 Ein Aufsatz über die Konkurrenz um religiös-säkulare Ordnung ist gegenwärtig in Arbeit. Einer der wichtigsten Klassiker ist hierbei natürlich Max Weber mit seinen Überlegungen zu Spannungen zwischen verschiedenen „Wertsphären“ (vgl. auch die Beiträge von Schwinn sowie Wohlrab-Sahr und Kaden in diesem Bd.).

15 Siehe zu einer mit der hier vertretenen Auffassung kompatiblen Analyse der Ausdifferenzierung von Religion und Politik Roßteutscher (2011). 
zustande, weil aktivere und sozial stärker vernetzte Personen eine höhere Wahrscheinlichkeit haben, sowohl mehr säkulare als auch mehr religiöse Aktivitäten aufzuweisen. Dies muss jedoch keineswegs einem langfristigen (d. h. longitudinalen) Ersetzungsmechanismus widersprechen, welcher dann doch zu einer negativen Korrelation führt. Eine zweite Anomalie besteht in der Tatsache, dass in verschiedenen Studien entweder keine oder positive Zusammenhänge zwischen Schicht und Religiosität nachgewiesen wurden (Stark und Bainbridge 1985). Würde aber unser Ansatz nicht erwarten lassen, dass Mitglieder höherer Schichten mehr Ressourcen aufweisen und daher stärker auf säkulare Optionen umschwenken könnten? Meines Erachtens führt es hier weiter, wenn man stärker verschiedene historische Randbedingungen unterscheidet. Religiös-säkulare Konkurrenz sagt nicht über alle Zeiten und Orte hinweg einen positiven Zusammenhang etwa von Einkommen und Säkularität voraus. Der hier vertretene analytische soziologische Ansatz verlangt vielmehr, dass für jeden zu erklärenden Fall genau die Optionen, Ressourcen, Präferenzen und Glaubensüberzeugungen ermittelt werden und erst dann erklärt wird. Es kann mithin sein, dass steigendes Einkommen in Westeuropa der 1960er Jahre zu vermehrter Säkularität führte, während es in den USA der 1940er Jahre gerade zum Übertritt in eine (Reputation versprechende) Denomination führte und ein erneutes religiöses Engagement zur Folge hatte. ${ }^{16}$ Ein drittes empirisches Problem besteht in der Tatsache, dass in manchen Studien eine religiös-säkulare Konkurrenz als Ursache von zu erklärenden religiösen Phänomenen behauptet wird; dass aber nicht immer eindeutig ist, ob das Phänomen nicht auch durch andere Faktoren hätte erklärt werden können. Mit anderen Worten: Die empirische Abgrenzung des Mechanismus von anderen Mechanismen wird oft nicht in überzeugender Weise geleistet. Hier kommt der Studie von Gruber und Hungerman (2008) eine besondere Bedeutung zu, da sie dieses Identifikationsproblem vorbildlich lösen. Es ist zu hoffen, dass viele weitere Studien dieser Art zeigen, wie groß die Reichweite solcher und ähnlicher Konkurrenzerklärungen ist.

Danksagung: Dieser Aufsatz ist eine Weiterentwicklung verschiedener Arbeiten der letzten Jahre (Stolz 2006, 2009a, b). Für Kritik und Anmerkungen danke ich Detlef Pollack, Matthias König, Christof Wolf sowie den Teilnehmenden der Autorentagung im Hinblick auf diesen Sonderband.

16 Zusätzlich mag es von Interesse sein, verschiedene Dimensionen von Religiosität zu unterscheiden, die je unterschiedlich mit Schicht korrelieren können. 


\section{Literatur}

Abbot, Andrew. 1988. The system of professions. An essay on the division of expert labor. Chicago: The University of Chicago Press.

Altermatt, Urs. 2009. Konfession, Nation und Rom. Metamorphosen im schweizerischen und europäischen Katholizismus des 19. und 20. Jahrhunderts. Frauenfeld: Huber.

Anyinam, Charles A. 1997. The role of female spiritualists in Africa. Persistence with change. Canadian Women Studies/Les Cahiers De La Femme 17:103-106.

Asad, Talal. 1993. The construction of religion as an anthropological category. Baltimore: The Johns Hopkins University Press.

Azzi, Corry, und Ronald Ehrenberg. 1975. Household allocation of time and church attendance. Journal of Political Economy 83:27-56.

Becker, Gary. 1990. The economic approach to human behavior. 1976. In The economic approach to human behavior Chicago, Hrsg. Gary Becker, 3-16. Chicago: The University of Chicago Press.

Berger, Peter L. 1990. The sacred canopy: Elements of a sociological theory of religion. 1967. New York: Anchor Books.

Boudon, Raymond. 1974. The logic of socological explanation. Suffolk: Penguin Education.

Bourdieu, Pierre. 1987. La dissolution du religieux. In Choses dites, Hrsg. Pierre Bourdieu, 117123. Paris: Editions de Minuit.

Bruce, Steve. 1993. Religion and rational choice: A critique of economice of religious behavior. Sociology of Religion 45:193-205.

Bruce, Steve. 1999. Choice and religion. A critique of Rational Choice Theory. Oxford: University Press.

Chaves, Mark. 1999. Religious congregations and welfare reform: Who will take advantage of „charitable choice“? American Sociological Review 64:836-846.

Chaves, Mark. 2006. All creatures great and small: Megachurches in context. Review of Religious Research 47:329-346.

Coleman, James S. 1990. Foundations of social theory. Cambridge: The Belknap Press of Harvard University Press.

Dixon, Robert et al. 2007. Catholics who have stopped attending mass. Fitzroy: Pastoral Projects Office. Australian Catholic Bishops Conference.

Dobbelaere, K. 2002. Secularization: An analysis at three levels. Bruxelles: Peter Lang.

Dow, James. 1986. Universal aspects of symbolic healing: A theoretical synthesis. American Anthropologist, New Series 88:56-69.

Ebaugh, Helen Rose. 1993. The growth and decline of catholic religious orders of women worldwide: The impact of women's opportunity structures. Journal for the Scientific Study of Religion 32:68-75.

Ebaugh, Helen Rose, Jon Lorence und Janet Saltzman Chafetz. 1996. The growth and decline of the population of catholic nuns cross-nationally, 1960-1990: A case of secularization as social structural change. Journal for the Scientific Study of Religion 35:171-183.

Einstein, Mara. 2008. Brands of faith. Marketing religion in a commercial age. London: Routledge.

Esser, Hartmut. 1999. Soziologie. Spezielle Grundlagen. Bd. 1: Situationslogik und Handeln. Frankfurt: Campus.

Froese, Paul, und Steven Pfaff. 2005. Explaining a religious anomaly: A historical analysis of secularization in eastern Germany. Journal for the Scientific Study of Religion 44:397-422.

Gill, Anthony, und Erik Lundsgaarde. 2004. State welfare spending and religiosity: A cross-national analysis. Rationality \& Society 16:399-436.

Gruber, Jonathan, und Daniel M. Hungerman. 2008. The church vs. the mall: What happens when religion faces increased secular competition? Quarterly Journal of Economics 123:831-862. 
Hedström, Peter. 2005. Dissecting the social. On the principles of analytical sociology. Cambridge: Cambridge University Press.

Hero, Markus. 2010. Die neuen Formen des religiösen Lebens. Eine institutionentheoretische Analyse neuer Religiosität. Würzburg: Ergon Verlag.

Hirschle, Jochen. 2010. From religious to consumption-related routine acetivities? Analyzing Ireland's economic boom and the decline in church attendance. Journal for the Scientific Study of Religion 49:673-687.

Hoover, Dwight W. 1991. Middletown: A case study of religious development, 1827-1982. Social Compass 38:273-284.

Hungerman, Daniel M. 2010. Rethinking religious competition. Working Paper.

Iannaccone, Laurence R. 1988. A formal model of church and sect. American Journal of Sociology 94:241-268.

Iannaccone, Laurence R. 1998. Introduction to the economics of religion. Journal of Economic Literature 36:1465-1495.

Inglehart, Ronald, und Christian Welzel. 2005. Modernization, cultural change, and democracy. The human development sequence. Cambridge: Cambridge University Press.

Kelley, Jonathan, und Nan Dirk De Graaf. 1997. National context, parental socialization, and religious belief: Results from 15 nations. American Sociological Review 62:639-659.

Kiefer, Bertrand. 2007. La guérison dans la médecine scientifique. In Quêtes de santé. Entre soins médicaux et guérisons spirituelles, Hrsg. Nicole Gauthier Durisch, Ilario Rossi und Jörg Stolz, 31-36. Genève: Labor et Fides.

Knoblauch, Hubert. 2009. Populäre Religion. Auf dem Weg in eine spirituelle Gesellschaft. Frankfurt a. M.: Campus Verlag.

Kroneberg, Clemens. 2011. Die Erklärung sozialen Handelns. Grundlagen und Anwendung einer integrativen Theorie. Wiesbaden: VS Verlag für Sozialwissenschaften.

Lambert, Yves. 2007. Dieu change en Bretagne. La religion à Limerzel de 1900 à nos jours. 1985. Paris: Les Editions du Cerf.

Lipset, Symour Martin. 1991. American exceptionalism reaffirmed. In Is America different? A new look at American exceptionalism, Hrsg. Byron E. Shafer, 1-45. Oxford: Clarendon Press.

Luckmann, Thomas. 1967. The invisible religion. New York: MacMillan.

Mcleod, Hugh. 2007. The religious crisis of the 1960s. Oxford: Oxford University Press.

Merton, Robert K. 1968. The bearing of sociological theory on empirical research. In Social theory and social structure, Hrsg. Robert K. Merton, 139-155. New York: The Free Press.

Moore, R. Laurence. 1994. Selling god. American religion in the marketplace of culture. New York: Oxford University Press.

Mottner, Sandra. 2007. Marketing and religion. In The Routledge companion to nonprofit marketing, Hrsg. Walter Wymer und Adrian Sargeant, 92-107. Oxford: Routledge.

Munoz, Laurence. 2003. Une histoire du sport catholique: la fédération sportive et culturelle de France: 1898-2000. Paris: L'Harmattan.

Norris, Pippa, und Ronald Inglehart. 2004. Sacred and secular. Religion and politics worldwide. Cambridge: Cambridge University Press.

Pahud De Mortanges, René. 2007. System und Entwicklungstendenzen des Religionsverfassungsrechts der Schweiz und des Fürstentums Liechtenstein. Zeitschrift für evangelisches Kirchenrecht 52:495-523.

Parsons, Talcott. 1991. The social system. 1951. Kent: Mackays of Chatham PLC.

Pickel, Gert. 2011. Religionssoziologie. Eine Einführung in zentrale Themenbereiche. Wiesbaden: VS Verlag für Sozialwissenschaften.

Pollack, Detlef. 2008. Introduction. Religious change in modern societies - Perspectives offered by the sociology of religion. In The role of religion in modern societies, Hrsg. Detlef Pollack und Daniel V.A. Olson, 1-21. New York: Routledge. 
Pollack, Detlef, und Daniel V.A. Olson. 2008. The role of religion in modern societies. New York: Routledge.

Putnam, Robert D. 2000. Bowling alone. The collapse and revival of American community. New York: Simon \& Schuster Paperbacks.

Putnam, Robert D., und David E. Campbell. 2010. American grace. How religion divides and Unites Us. New York: Simon \& Schuster.

Riesebrodt, Martin. 2007. Cultus und Heilsversprechen. Eine Theorie der Religionen. München: C.H. Beck.

Roßteutscher, Sigrid. 2011. Die konfessionell-religiöse Konfliktlinie zwischen Säkularisierung und Mobilisierung. PVS Sonderheft 45:111-133.

Stark, Rodney, und William Sims Bainbridge. 1985. The future of religion. Berkeley: University of California Press.

Stark, Rodney, und Roger Finke. 2000. Acts of faith. Explaining the human side of religion. Berkeley: University of California Press.

Stark, Rodney, und Laurence Iannaccone, R. 1994. A supply-side reinterpretation of the „Secularization of Europe“. Journal for the Scientific Study of Religion 33:230-252.

Stolz, Jörg. 2006. Salvation goods and religious markets: Integrating Rational Choice and Weberian perspectives. Social Compass 53:13-32.

Stolz, Jörg. 2009a. Explaining religiosity: Towards a unified theoretical model. British Journal of Sociology 60:345-376.

Stolz, Jörg. 2009b. A silent battle. Theorizing the effects of competition between churches and secular institutions. Review of Religious Research 51:253-276.

Stolz, Jörg, und Edmée Ballif. 2010. Die Zukunft der Reformierten. Gesellschaftliche Megatrends - kirchliche Reaktionen. Zürich: TVZ.

Stolz, Jörg, Olivier Favre, Caroline Gachet und Emmanuelle Buchard. 2012. Le phénomène évangélique. Genève: Labor et Fides.

Stolz, Jörg, Judith Könemann, Mallory Schneuwly Purdie, Thomas Englberger und Michael Krüggeler. 2013. Religion und Spiritualität in der Ich-Gesellschaft. Vier Gestalten des (Un-)Glaubens. Zürich: TVZ/NZN.

Stolz, Jörg, und Jean-Claude Usunier. 2013. Religions as brands. New Perspectives on the marketization of religion and spirituality. London: Ashgate.

Taylor, Charles. 2007. A secular age. Cambridge: The Belknap Press of Harvard University Press.

Ukah, Asonzeh. 2008. Religion and healing: A West African perspective. Research Paper, BIGSAS Interdisciplinary Research Seminar 5 June S. 1-16.

Voas, David. 2010. Value liberalization or consumption: Comment on Hirschle's analysis of Ireland's economic boom and the decline in church attendance. Journal for the Scientific Study of Religion 49:671-673.

Wallis, Roy, und Steve Bruce. 1995. Secularization: The orthodox model. In The sociology of religion, Hrsg. Steve Bruce, 693-715. Aldershot: Elgar.

Weber, Max. 1985. Wirtschaft und Gesellschaft. 1922. Tübingen: J.C.B. Mohr.

Jörg Stolz, 1967, Prof. Dr., Institut de Sciences Sociales des Religions Contemporaines, Forschungsgebiete: Säkularisierung, Religiöser Markt, Evangelikalismus, Soziologische Erklärung, Islamophobie, Analytische Soziologie, Mixed Methods,. Veröffentlichungen: Explaining Religiosity: Towards a Unified Theoretical Model. British Journal of Sociology 60, 2009. All Things Are Possible. Towards a Sociological Explanation of Pentecostal Miracles and Healings. Sociology of Religion 72, 2011. 